\section{Single-step retrieval of a proximally migrated biliary stent}
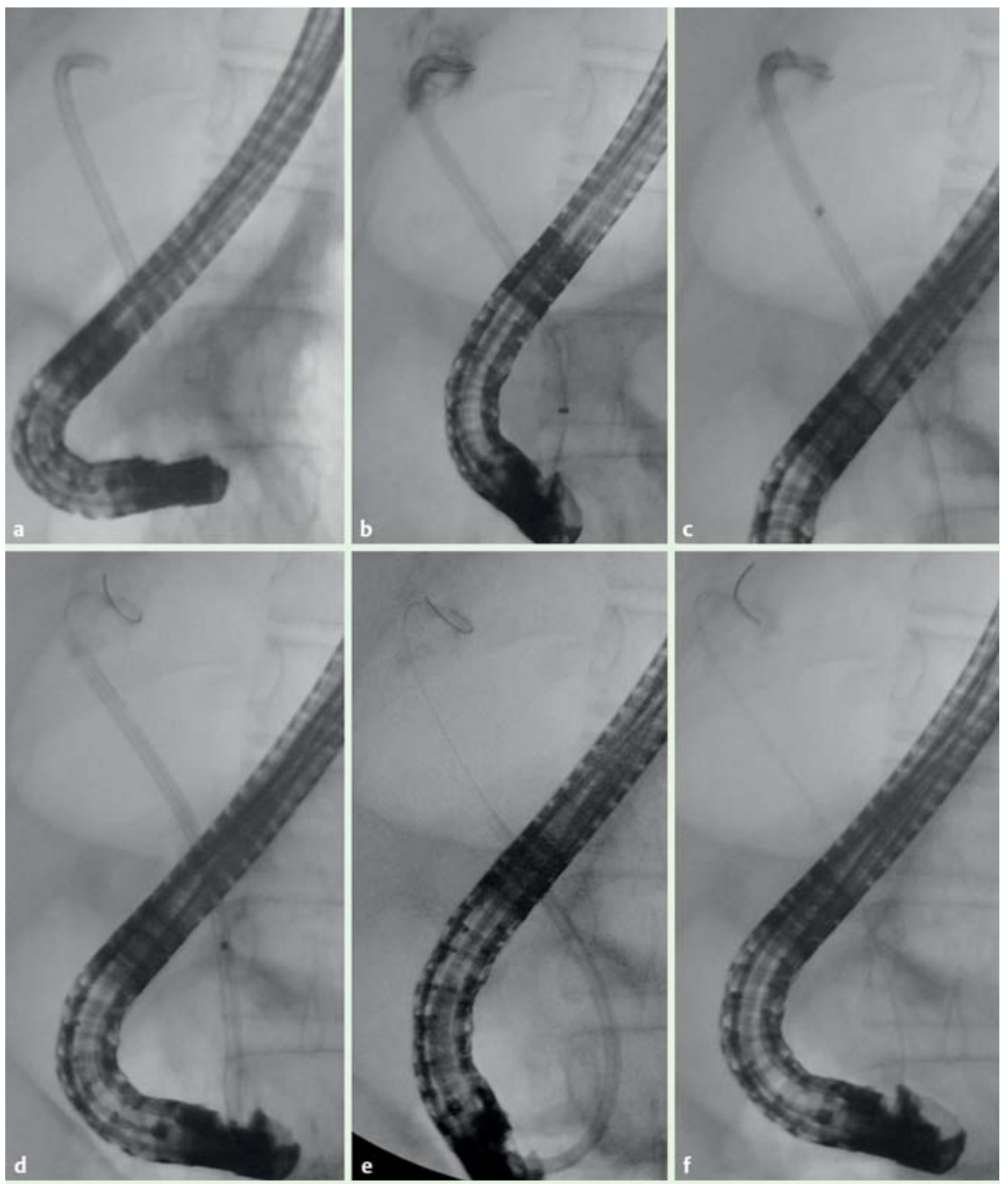

Fig. 1 X-ray views of the process of retrieving a proximally migrated stent: $\mathbf{a}, \mathbf{b}$ 0.035 -inch guidewire passed through the proximally migrated stent; $c$ dilation balloon inserted over the guidewire and advanced to the distal portion of the stent; $\mathbf{d}, \mathbf{e}$ balloon - stent system withdrawn through the operative channel; $\mathbf{f}$ guidewire left in situ for any further applications needed.

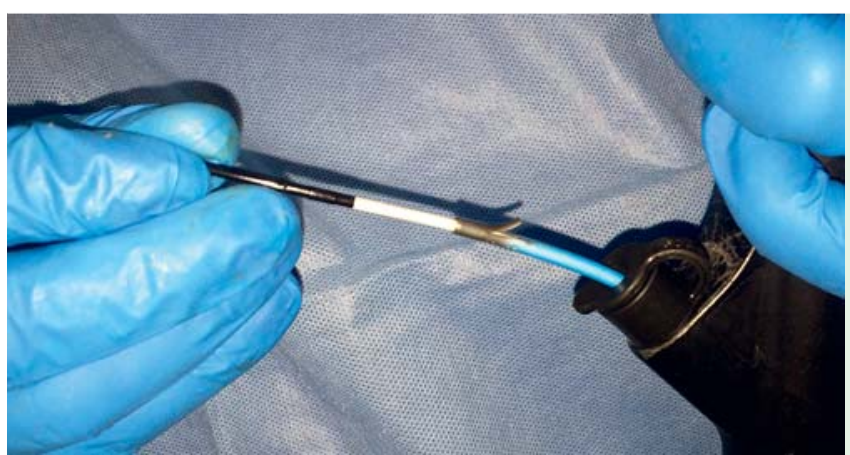

Endoscopic biliary stent placement is a well-established procedure for biliary drainage. However, it has been shown that approximately $5 \%$ of plastic stents placed in the biliary tract migrate proximally [1]. The endoscopic retrieval of a proximally migrated biliary stent is technically challenging and occasionally unsuccessful. Several techniques for retrieving proximally migrated plastic stents have been reported [2]. We report here a novel retrieval technique, in which a biliary dilation balloon was used to pull out in one step a trapped plastic stent, previously placed to treat an anastomotic biliary stricture in a patient with a liver transplant.

A 0.035-inch guidewire (Acrobat; Cook Ireland Ltd., Limerick, Ireland) was passed through the $10-\mathrm{Fr}, 9-\mathrm{cm}$ proximally $\mathrm{mi}-$ grated stent (Cotton-Leung; Cook Ireland Ltd.) ( Fig. 1 a, b). A dilation balloon with a diameter of $4 \mathrm{~mm}$ and a length of $4 \mathrm{~cm}$ (Hurricane RX Biliary Balloon Dilatation Catheter; Boston Scientific, Marlborough, Massachusetts, USA) was coaxially inserted over the guidewire and advanced to the distal portion of the stent ( $\bullet$ Fig. $1 \mathrm{c}$ ). It was then inflated to nominal pressure. The inflated balloon was anchored inside the stent, resulting in a firm, retrievable coaxial system. With the elevator of the scope (TJF-Q180V; Olympus Europa, Hamburg, Germany) completely opened, the balloon-stent system was withdrawn through the operative channel (diameter of $4.2 \mathrm{~mm}$ ) ( $\boldsymbol{F i g .} \mathbf{1 d}, \mathrm{e}$ ), with the guidewire left in situ for any further applications that might be needed ( $\bullet$ Fig. $1 \mathbf{f}$ ).

Inspired by the timeless suggestions advanced by Chaurasia et al. in 1999 [2], we report an improved technique of retrieval with the use of a biliary dilation balloon instead of an extraction balloon. The technique results in the safe, single-step retrieval of a migrated stent from the bile duct directly into the endoscopist's hand (৫ Fig.2), avoiding potential damage to the bile duct and the need for withdrawal of the duodenoscope.

Endoscopy_UCTN_Code_TTT_1AR_2AZ

\section{Competing interests: None}


Antonino Granata, Gabriele Curcio, Dario Ligresti, llaria Tarantino, Luca Barresi, Mario Traina

Endoscopy Service, Department of Diagnostic and Therapeutic Services, IRCCS - ISMETT (Istituto Mediterraneo per i Trapianti e Terapie ad alta specializzazione), Palermo, Italy

\section{References}

1 Johanson JF, Schmalz MJ, Geenen JE. Incidence and risk factors for biliary and pancreatic stent migration. Gastrointest Endosc 1992; 38: 341 - 346

2 Chaurasia OP, Rauws EA, Fockens $P$ et al. Endoscopic techniques for retrieval of proximally migrated biliary stents: the Amsterdam experience. Gastrointest Endosc 1999; 50: $780-785$

\section{Bibliography}

DOI http://dx.doi.org/ 10.1055/s-0034-1391908 Endoscopy 2015; 47: E284-E285

(c) Georg Thieme Verlag KG

Stuttgart · New York

ISSN 0013-726X

Corresponding author Antonino Granata, MD IRCCS - ISMETT

Via Tricomi 5

90127 Palermo

Italy

Fax: +39-091-21-92-400

(specify Endoscopy Service)

agranata@ismett.edu 